\title{
Prevalence of Dementia and Alzheimer's Disease in a Havana Municipality: A Community-Based Study among Elderly Residents
}

Juan de Jesús Llibre, MD, PhD, Yuriem Fernández, MS, Beatriz Marcheco, MD, PhD, Nereyda Contreras, MD, Ana M. López, MD, MS, Marta Otero, BS, Isis Gil, MD, MS, Milagros Guerra, MD, MS, Milagros García, MD, MS, Héctor Bayarre, MD, PhD

\begin{abstract}
Introduction Approximately 24.2 million persons throughout the world suffer dementia with 4.6 million new cases reported annually. Only $10 \%$ of dementia and Alzheimer's disease studies are conducted in developing countries where $66 \%$ of sufferers live. Cuba, a developing country, exhibits health indicators similar to those of developed nations. Its population of 11.2 million is aging rapidly: by the year 2020 it is estimated that personas aged $\geq 60$ years will comprise $21.6 \%$ of the population, making Cuban society the "oldest" in Latin America.
\end{abstract}

Objectives Ascertain and characterize behavior of dementia, its etiologies and risk factors in persons aged $\geq 65$ years in the Havana City municipality of Playa.

Method A two-phase, cross-sectional, door-to-door study was conducted in the municipality targeting all persons aged $\geq 65$ years, achieving a $96.4 \%$ response rate $(n=18,351)$. Folstein Mini Mental State Examination (MMSE), Hughes Clinical Dementia Rating (CDR) and a structured interview on risk factors were applied. DSM-IV,
NINCDS-ADRDA and NINDS-AIREN criteria were used to determine dementia diagnosis, as well as other criteria for diagnosing Alzheimer's and other specific forms of dementia.

Results Dementia prevalence was $8.2 \%$ of adults aged $\geq 65$ years, with a slight predominance in males. The most frequent cause of dementia was Alzheimer's disease, followed by mixed dementias. Dementia-associated risk factors were: history of stroke, hypertension, depression, skull-brain trauma, family history of dementia, low educational level and advanced age.

Conclusions This study corroborates that dementia and Alzheimer's disease constitute an important and growing health problem for our country due to the accelerated aging of the Cuban population. It also underlines the importance of early diagnosis and proper treatment of hypertension and other vascular risk factors, as well as the need for a national public health program for the prevention and early diagnosis of dementia and Alzheimer's disease, targeting elderly and at-risk populations.

Keywords: Brain diseases, dementia, mental disorders, neurodegenerative diseases, Alzheimer's disease, aging

\section{INTRODUCTION}

Estimates based on a systematic review of prevalence data and an experts' consensus indicate that approximately 24.2 million persons worldwide were afflicted with dementia by 2005 , with 4.6 million new cases every year,[1] similar to annual incidence of non-fatal stroke.[2] Global prevalence is expected to double every twenty years, reaching over 80 million by 2040 . However, the increase in developing regions (300\%) will be much sharper than in developed regions (100\%), and in Latin America will exceed that of any other region. In $2001,60 \%$ of people with dementia lived in low and middle income countries, a proportion that is expected to reach $71 \%$ by 2040 .[1]

Recent studies put the cost of dementia worldwide at US $\$ 315.4$ billion annually,[3] with North America and Europe exhibiting the greatest financial burden. As the number of persons with dementia doubles every 20 years, costs can be expected to rise proportionately. This financial burden, combined with the challenge of larger elderly populations, will produce dramatic changes in health systems the world over.

Only $10 \%$ of studies on dementia and Alzheimer's disease are conducted in developing countries where $66 \%$ of dementia sufferers live.[4] Thus, further research on non-communicable chronic diseases in developing countries is required, focusing not only on early mortality, but also on disability-adjusted life years (DALYs). [4,5] According to a 2003 report on global disease burden, dementia is the main contributor to DALYs in persons aged $\geq 60$ years, accounting for $11.2 \%$-surpassing stroke (9.5\%), musculoskeletal diseases (8.9\%), cardiovascular disease $(5.0 \%)$ and cancer (2.4\%).[6]

Cuba is a developing country with health indicators similar to those of developed countries and a rapidly aging population of 11.2 million. By the year 2020 Cuba will have the oldest population in Latin America, with adults aged $\geq 60$ years accounting for $21.6 \%$ of total population.[7]

From September through December, 2003, as part of the National Program for Attention to Disabled Persons, a study was conducted in the Playa Municipality of Havana City Province to ascertain and characterize the behavior of Alzheimer's disease and other dementias, as well as associated risk factors, in residents aged $\geq 65$ years (Playa Study on Dementia and Alzheimer's, abbreviated in Spanish as EDAP).

The 38-square-kilometer $\left(38.17 \mathrm{~km}^{2}\right)$ Playa Municipality is an urban area in western Havana that had a resident population of 185,501 at the time of the study, according to public health records. 


\section{MATERIALS AND METHODS}

Study design A two-phase, cross-sectional study was conducted. An EDAP coordinating group was formed, led by the National Group for Attention to Disabled Persons and comprised of specialists and researchers from the National Medical Genetics Center, Cuban Neuroscience Center, the Higher Institute of Medical Sciences of Havana, and the Playa Municipal Health Department.

The coordinating group developed the research protocol, survey questionnaires, and procedures manual for the study; coordinated training of specialists, family doctors and other participating health professionals; and prepared partial and final reports. It also monitored implementation, interview quality, data processing, and statistical analysis.

The Havana City Provincial Health Department and its Older Adults and Social Welfare Section participated in the coordinating group meetings and provided family doctors, psychiatrists, geriatricians, neurologists and psychologists for the study.

Data gathering began in September 2003 and was completed in December of the same year.

Ethical considerations All elderly participants and family members provided written informed consent (either personally and/or by a caregiver when the person did not have the capacity to consent). The research protocol was approved by the Ethics Committees of the participating institutions and of the National Program for Attention to Disabled Persons.

Phase One From September through November 2003, the coordinating group trained and certified 335 family doctors from all nine polyclinics (community-based multi-specialty clinics with geographic catchment areas serving the total population) in Playa Municipality in application of the survey questionnaires, the research protocol, and diagnosis of cognitive disorders and dementia.

Family doctors visited the total resident population of persons aged $\geq 65$ years in Playa Municipality, based on clinical records provided by family doctors and polyclinics. These registries were supplemented with a door-to-door census conducted to confirm or rectify age, gender and name of all persons aged $\geq 65$ years.

In a second visit, the survey questionnaire was applied, as well as a Mini Mental State Examination (MMSE),[8] Clinical Dementia Rating scale (CDR),[9] and physical examination. Relatives living with elders were also interviewed and, if necessary, nearest neighbors. A total of 18,351 adults aged $\geq 65$ years were surveyed for a response rate of $96.4 \%$. Causes for non-response included refusal to participate in the study or failure to contact the person after three home visits.

Based on this clinical evaluation, participants were classified in three groups: A) elderly persons with no cognitive decline, potentially normal (normal MMSE $\geq 17$ for those who did not complete primary-level education; $\geq 24$ for those who completed at least secondary school, and normal CDR score $=0$ ); B) elderly persons with suspected dementia (MMSE $<17$ for those who did not complete primary-level education, or $<24$ for those who completed at least secondary school, and a CDR score compatible with a mild, moderate or severe dementia); and C) elderly persons with possible cognitive disorder (MMSE $\geq 17$ for persons who did not complete primary-level education, $\geq 24$ for those who completed at least secondary school, and an uncertain CDR score).

Phase Two During November and December, 2003, a team of 72 specialists (geriatricians, psychiatrists, internists, psychologists and disability specialists) previously trained for the study visited and examined each of the elderly persons in the three groups classified in Phase One.

For the purposes of the study, Group A was reduced by randomly selecting $20 \%(n=2,421)$ of the 12,107 persons without cognitive decline identified in Phase One. Group B (elderly persons with suspected dementia) consisted of 3,030 persons, and 3,214 were classified in Group C (elderly adults with possible cognitive disorder). Thus, a total of 8,665 persons aged $\geq 65$ years were examined during Phase Two. Response rate in Phase Two was 94.5\%; non-response was associated with refusal to participate, failure to contact the participant after three home visits, and hospitalization or death.

Clinical evaluation was conducted by a physician and one other team member (psychologist or disability specialist) in participants' homes, consisting of: 1) cognitive evaluation using the MMSE, CDR scale and the Consortium to Establish a Registry for Alzheimer's Disease (CERAD) modified 10 word list learning tasks,[10] and the Activities of Daily Life (ADL) and Instrumental Activities of Daily Living (IADL) scales[11] for assessing functional status; 2) a semi-structured informant interview; and 3) neuroimaging studies (CAT) and clinical tests (hemogram, glycemia, creatinine, liver function, thyroid hormone and determination of vitamin B12 levels) if considered necessary for diagnosing probable cause of dementia.

Diagnosis During Phase Two, definitive diagnosis of dementia and its main causes was reached by consensus of the two principal investigators after reviewing clinical evaluations and data provided by the specialists participating in the study.

Dementia diagnosis was based on DSM-IV criteria[12] and others for specific forms of dementia, particularly the criteria of the $\mathrm{Na}$ tional Institute of Neurological and Communicative Disorders and Stroke-Alzheimer's Disease and Related Disorders Association (NINCDS-ADRDA)[13] for Alzheimer's disease, and the criteria of the National Institute of Neurological Disorders and StrokeAssociation Internationale pour la Recherche et l'Ensignement en Neurosciences (NINDS-AIREN)[14] for vascular dementia, as well as the criteria used to determine senile dementia of Lewy body type.[15]

One group of Alzheimer's patients developed symptoms of vascular dementia, generally following stroke, with abrupt worsening of cognitive decline. These patients were classified as suffering from 
Alzheimer's disease associated with cerebrovascular disease (mixed dementia).

In cases with a prior family history of dementia, the family unit was studied through a genealogical tree.

Variables studied The following variables were used to describe participants: age (years), skin color (white, black, mixed), marital status, educational level (illiterate, incomplete primary school, primary school completed, secondary school completed, preuniversity education completed, and university education completed), years of schooling, employment status, personal disease history (ischemic heart disease, hypertension, diabetes mellitus, cerebroovascular disease, hyperlipoproteinemia), family history of dementia, toxic habits (alcohol consumption, smoking), presence of cognitive disorders, presence of dementia, severity of dementia (mild, moderate, severe) according to the dementia clinical rating scale, type of dementia (Alzheimer's, vascular, mixed, other etiology), and degree of dependency in performing everyday activities.

Analysis Dementia prevalence was calculated by age group, sex and probable etiology. Based on DSM-IV criteria, prevalence in this study was compared to that obtained in EURODEM, a metaanalysis of 12 European studies,[16] by indirect age standardization, standardized morbidity ratio (SMR) and 95\% confidence intervals. Dementia prevalence in the Playa study was also compared to that obtained for the Cuban population and for Latin America in the 10/66 Research Group's study[17] (indirect age standardization).

Since this is a cross-sectional study, analysis of dementiaassociated risk factors was carried out on the assumption that the factor or exposure preceded the onset of dementia by a period of three years, in order to lower the possibility of inverse causality.

In order to determine the influence of a number of risk factors on the presence of dementia, an initial univariate analysis was conducted of each of the explanatory or independent (qualitative) variables and of the response or dependent variable (dementia). In case of significant association $(p<0.05)$, or according to expert criteria, the independence test (Chi-square) was included in a later analysis.

Variables included in the model were: prior history of cerebrovascular disease (stroke) diagnosed by a medical specialist, hypertension, prior treatment for depression, skull trauma with loss of consciousness, prior history of diabetes mellitus, family history of dementia, employment status, educational level, age, history of diabetes mellitus, and marital status. For quantitative variables, a mean comparison test

$\mathrm{Cl}$ : Confidence Interval

$\mathrm{Cl}$ : Confidence Interval was used (in independent samples) with unknown variances. To avoid introduction of estimation errors due to excessive correlation among independent variables (co-linearity), association was determined by means of an independence test (Chi-square) for quantitative variables accompanied by a correlation coefficient (Cramer's Phi or $\mathrm{V}$ contingency tables if one or more degrees of freedom existed), and Pearson's linear correlation coefficient for quantitative variables. Correlation coefficient values $>0.8$ were considered significant. Multiple Logistic Regression (MLR) with binary response was later applied.

For each dementia case, four controls were selected from among the elderly persons identified without cognitive decline (Group A). In this risk association analysis, only patients with mild or moderate dementia were included (determined by CDR scale) for a total of 1,396 patients and 5,584 controls. SPSS package for Windows version 13.0 was used for data analysis.

In all the hypothesis tests conducted, a $5 \%(p \leq 0.05)$ significance level was used. For the multivariate analyses, only participants with no missing data for all independent variables were included.

\section{RESULTS}

The average age of participants was 74.64 years (minimum 65 years and maximum 105 years). Calculation of dementia prevalence in elderly persons living in Playa Municipality is presented in Table 1.

Dementia exhibited a prevalence of $8.2 \%$ in adults aged $\geq 65$ years, with similar rates in both men and women, and increased with age in both sexes. Prevalence was $3.2 \%$ in the $65-69$ age group and $30.5 \%$ in the $\geq 90$ age group.

Table 1: Prevalence of Dementia, Playa Municipality, Havana, by Age and Sex

\begin{tabular}{|c|c|c|c|c|c|c|c|c|c|c|}
\hline \multirow[t]{3}{*}{ Age Group } & \multicolumn{3}{|c|}{ Men } & \multicolumn{3}{|c|}{ Women } & \multicolumn{4}{|c|}{ Total } \\
\hline & \multirow{2}{*}{ N (total) } & \multicolumn{2}{|c|}{ (Dementia) } & \multirow{2}{*}{ N (total) } & \multicolumn{2}{|c|}{ (Dementia) } & \multirow{2}{*}{ N (total) } & \multicolumn{3}{|c|}{ Dementia } \\
\hline & & $\mathbf{N}$ & $\%$ & & $\mathbf{N}$ & $\%$ & & $\mathrm{~N}$ & $\%$ & $95 \% \mathrm{Cl}$ \\
\hline $65-69$ & 1973 & 57 & 2.9 & 3442 & 114 & 3.3 & 5415 & 171 & 3.2 & $2.7-3.6$ \\
\hline $70-74$ & 1123 & 40 & 3.6 & 2956 & 139 & 4.7 & 4079 & 179 & 4.4 & $3.7-5.0$ \\
\hline $75-79$ & 1213 & 75 & 6.2 & 2626 & 194 & 7.4 & 3839 & 269 & 7.0 & $6.2-7.8$ \\
\hline 80-84 & 1052 & 126 & 12.0 & 1510 & 188 & 12.5 & 2562 & 314 & 12.3 & $11.0-13.0$ \\
\hline 85-89 & 836 & 155 & 18.5 & 957 & 209 & 21.8 & 1793 & 364 & 20.3 & $17.2-23.4$ \\
\hline$\geq 90$ & 311 & 84 & 27.0 & 352 & 118 & 33.5 & 663 & 202 & 30.5 & 26.9-34.0 \\
\hline Total & 6508 & 537 & 8.3 & 11,843 & 962 & 8.1 & 18,351 & 1499 & 8.2 & $7.8-8.6$ \\
\hline
\end{tabular}

Source: Playa Study on Dementia and Alzheimer's (EDAP)

Table 2: Dementia Prevalence by Educational Level

\begin{tabular}{|l|r|r|r|r|}
\hline Educational Level & N (total) & Dementia & Prevalence (\%) & \multicolumn{1}{c|}{$95 \% \mathbf{C l}$} \\
\hline Illiterate* & 355 & 128 & 36.1 & $31.1-40.1$ \\
\hline Low $†$ & 8960 & 1062 & 11.9 & $11.7-12.1$ \\
\hline High $\ddagger$ & 9036 & 309 & 3.4 & $3.0-3.8$ \\
\hline
\end{tabular}

*Illiterate: cannot read or write despite absence of hearing or visual disability

†Low: 7th grade or less completed

†High: 8th grade or more completed

Source: Playa Study on Dementia and Alzheimer's (EDAP) 
Table 3: Dementia Prevalence: EDAP and EURODEM (DSM-IV Criteria) and Cuba and Seven Latin American Countries (10/66 Criteria)

\begin{tabular}{|c|c|c|c|c|}
\hline Study & $\begin{array}{c}\text { Diagnostic } \\
\text { Criteria }\end{array}$ & $\begin{array}{l}\text { Prevalence } \\
(\%)\end{array}$ & $\begin{array}{l}\text { Data } \\
\text { Source }\end{array}$ & $\begin{array}{c}\text { SMR } \\
(95 \% \mathrm{Cl})\end{array}$ \\
\hline $\begin{array}{l}\text { EDAP }(\mathrm{N}=18,351) \\
\text { Crude Prevalence }\end{array}$ & DSM-IV & $8.2(7.8-8.6)$ & - & - \\
\hline $\begin{array}{l}\text { Standardized } \\
\text { Prevalence }^{*}\end{array}$ & DSM-IV & $8.7(8.2-9.4)$ & - & - \\
\hline $\begin{array}{l}\text { SMR† } \\
\text { EURODEM }\end{array}$ & DSM-IV & 6.4 & EURODEM Studies & $135(119-152)$ \\
\hline $\begin{array}{l}\text { SMR 10/66 } \\
\text { Cuban Prevalence§ }\end{array}$ & $10 / 66$ & $10.8(9.7-12.0)$ & 10/66 Study & $80(72-91)$ \\
\hline $\begin{array}{l}\text { SMR 10/66 } \\
\text { Latin American Prevalence } \|\end{array}$ & $10 / 66$ & $7.3(6.8-7.8)$ & 10/66 Study & $119(110-132)$ \\
\hline
\end{tabular}

*Direct standardization for age, sex, and educational level

†SMR = standardized morbidity ratio

$\ddagger$ Age-standardized prevalence adjusted against EURODEM[16]

§Age-standardized prevalence adjusted against Cuban 10/66 prevalence[17]

||Age-standardized prevalence adjusted against Latin American 10/66 prevalence[18]

$\mathrm{Cl}$ : Confidence Interval

SMR is the ratio of the number of dementia cases observed divided by the number of cases expected. The number observed was obtained from the number of EDAP cases surveyed, and the number expected was obtained from the prevalence by age and sex in the EURODEM study,[16] prevalence by age in the 10/66 Cuban study[17] or prevalence by age and sex in the 10/66 Latin American study.[18] A standardized morbidity ratio (SMR) of 100 implies that dementia prevalence observed in the EDAP universe is similar to that of the reference population; an SMR $<100$ implies that the EDAP dementia prevalence is less than that of the reference population, and an SMR $>100$ implies that the dementia prevalence is greater than that of the reference population.

Source: Playa Study on Dementia and Alzheimer's (EDAP), EURODEM studies, 10/66 Dementia population based studies.

Participants' educational level was high: $49.2 \%$ had completed at least secondary school, and only $1.9 \%$ lacked formal education. However, dementia prevalence was high among those with no schooling (36.1\%) and 10 times lower among those with higher levels of education (3.4\%) (Table 2).

Table 3 compares EDAP results with those of other studies. According to DSM-IV criteria, dementia prevalence by age group in Playa Municipality, Havana, (EDAP) proved higher than that reported by EURODEM,[16] with a morbidity ratio standardized by age and sex (SMR) of 135. When compared to the 10/66 Group's prevalence study using the 10/66 Dementia Diagnostic Algorithm,[17] EDAP results were slightly lower than those reported for Cuba and greater than those for Latin America.

As can be observed in Table 4, Alzheimer's disease prevailed among the causes of dementia, although approximately $50 \%$ corresponded to mixed and vascular dementia. Less than $1 \%$ of the cases exhibited dementias related to potentially curable or re-

Table 4: Probable Causes of Dementia in Playa Municipality, Havana, by Frequency of Diagnosis

\begin{tabular}{|l|r|r|}
\hline Probable Cause & Total Cases & \multicolumn{1}{|c|}{$\%$} \\
\hline Alzheimer's disease & 696 & 46.4 \\
\hline Mixed dementia & 423 & 28.2 \\
\hline Vascular dementia & 331 & 22.1 \\
\hline Dementia related to Parkinson's disease & 33 & 2.2 \\
\hline Reversible dementias & 11 & 0.8 \\
\hline Lewy body type & 5 & 0.3 \\
\hline TOTAL & 1499 & 100.0 \\
\hline
\end{tabular}

Source: Playa Study on Dementia and Alzheimer's (EDAP) versible causes, particularly hypothyroidism (3 participants), vitamin B12 deficit (4) and chronic alcoholism (4).

Identification of dementia risk factors in the elderly of Playa Municipality. Table 5 shows the association between various risk factors and dementia. EDAP revealed that probability of dementia is significantly influenced by a prior history of stroke, hypertension, depression, skull-brain trauma with prolonged loss of consciousness, family history of dementia, unemployment, low educational level, and aging.

The highest OR among binary qualitative variables was observed in cases with a prior history of stroke $(\mathrm{OR}=5.89)$ indicating nearly 6 times greater probability of dementia in these elderly persons. For the quantitative variable of age, an OR of 1.11 was observed, indicating that with every passing year, dementia is 1.1 times more likely.
Table 5: Risk Factor Association with Dementia in EDAP: Multiple Logistic Regression Analysis

\begin{tabular}{|l|r|r|r|}
\hline Variable/Risk Factor & Odds Ratio (OR) & $95 \% \mathrm{Cl}$ & p value \\
\hline History of stroke & 5.89 & $4.50-7.72$ & 0.000 \\
\hline Hypertension & 2.45 & $1.10-5.41$ & 0.050 \\
\hline History of depression & 2.02 & $1.53-2.67$ & 0.000 \\
\hline Skull trauma & 2.06 & $1.33-3.17$ & 0.002 \\
\hline Family history of dementia & 1.75 & $1.48-2.06$ & 0.000 \\
\hline Unemployment & 2.12 & $1.31-3.42$ & 0.020 \\
\hline Educational level & 1.3 & $1.19-1.41$ & 0.000 \\
\hline Age & 1.11 & $1.01-1.12$ & 0.000 \\
\hline Diabetes mellitus & 1.26 & $0.98-1.63$ & 0.060 \\
\hline Marital status & 1.04 & $0.83-1.30$ & 0.690 \\
\hline
\end{tabular}

Cl: Confidence Interval

Source: Playa Study on Dementia and Alzheimer's (EDAP)

A history of dementia in first- and second- degree relatives constitutes a risk factor for Alzheimer's disease: in this study, 250 participants with dementia $(14.7 \%$ of dementia cases) reported a family history of dementia of which 193 (77.2\%) presented Alzheimer-type dementia.

\section{DISCUSSION}

EDAP is one of the most extensive studies of dementia and Alzheimer's disease in Cuban and Latin American populations. Differences in dementia prevalence among countries have been reported in various studies conducted in Latin America, ranging from $3 \%$ in Colombia to $13 \%$ in Venezuela.[19-24] Such country differences have also been observed in prevalence studies 
in developed countries.[25,26] However, caution is advised when comparing such findings, since differences are often related to the diagnostic criteria used, type of sample or study design (one or two phases).[27,28]

A global analysis of results reported from studies conducted in populations aged $\geq 65$ years in different regions of the world indicate that the prevalence of dementia found in our study is slightly higher than the $7.6 \%$ crude prevalence rate reported for Europe and within the $6 \%-10 \%$ range reported for North America.[16,25] A recently published survey of 15,000 persons aged $\geq 65$ years from 11 regions in seven developing countries, including India and China, reported a dementia prevalence in Latin American urban areas similar to that of Europe and the USA, and lower in China and India.[18] The Canadian Study of Health and Aging (CSHA), which included 10,263 persons aged $\geq 65$ years, observed a global prevalence of $8.2 \%$.[26]

A greater prevalence of dementia and Alzheimer's disease has also been reported among people in the Caribbean, and among Caribbean residents of the United States and the United Kingdom, compared to non-Caribbean residents of those countries in studies conducted using the same design.[24,29-32] Genetic or environmental factors may explain these differences.

In Cuba, a door-to-door study was conducted from January through March 2004 in Santa Clara Municipality (located in the central part of the island), using the same design as the EDAP in Havana. A total of 20,064 adults aged $\geq 65$ years were surveyed (93.1\% response rate), and a dementia prevalence of $7.1 \%(95 \%$ $\mathrm{Cl}: 6.7 \%-7.5 \%)$ was reported, with a predominance among women.[33] A recent single-phase study of 3,000 Cubans aged $\geq 65$ years reported an even greater dementia prevalence of $10.8 \%$ (95\% Cl: 9.7\%-12.0\%), based on the 10/66 Research Group criteria; using DSM-IV criteria, however, this figure dropped to $6.4 \%$ (Cl 95\%: 5.6\%-7.4\%).[17]

In the latter studies, clinical diagnosis was made by trained specialists using the broader criteria developed by the 10/66 Research Group rather than the more restrictive DSM-IV diagnostic criteria,[34] which tends to exclude mild cases of dementia. DSM-IV criteria stipulate that memory and other domains of cognitive function must be affected and must substantially interfere with a person's professional and social life. However, memory disorders are often not apparent, are attributed to aging or simply not detected by the individual's closest relatives until more advanced stages of dementia set in.

Cultural factors and knowledge about dementia therefore play an important role in this process. One of the few studies examining this aspect is the Canadian Study on Health and Aging,[26] which reported a higher prevalence of dementia in persons aged $\geq 65$ years, based on clinical consensus more than on DSM-IV criteria.

The high prevalence of dementia found in the EDAP study is associated with the advanced age, frequency of chronic diseases, and vascular risk factors in the Cuban population. The increase in dementia with increasing age and other risk factors observed are similar to that reported in the literature.[35-42]

Low educational level, particularly illiteracy, is consistently associated with high rates of dementia,[35,36] which presupposes that education could exert a significant protective effect against this disease through a cognitive reserve mechanism.

A possible limitation of this study is that dementia diagnosis in illiterate people or those with little education is very difficult, resulting in a tendency to overestimate prevalence in this group. However, we believe this possibility was minimized by the fact that interviewers were properly trained and had prior experience in dementia diagnosis, and because lower MMSE cut-off points were used in individuals with a low educational level. MMSE and CDR are used extensively in community studies.[8,11,36] MMSE is widely used in Cuba and internationally[8,25,35] with good concurrent reliability.

Reliability of the study's results are enhanced by its design and community-based population approach. Although this is a twophase study, selection of a $20 \%$ sample of elderly participants who tested negative in Phase One, and the fact that interviews were conducted by trained physicians and health professionals, minimized problems associated with under-reporting and loss of cases commonly found in two-phase studies.[28] Each clinical dementia diagnosis was determined by consensus, based on internationally accepted criteria, including neuropsychological tests, informants' reports of functional and cognitive decline, laboratory tests and neuroimaging studies when necessary.

The strategy of examining the total elderly population in a municipality, although relatively costly and requiring greater resources, is consistent with the Cuban public health system's active screening policy, which maximizes response rates, facilitating early diagnosis and development of intervention programs targeting persons with dementia, at-risk populations, family orientation, and longitudinal follow-up of the population.

In this study, a number of modifiable conditions proved to be risk factors, including cerebrovascular disease, hypertension, skullbrain trauma, depression and low educational level. This confirms the fact that both prevention and adequate control of hypertension and cerebrovascular disease may have implications for reducing cognitive decline and dementia.

At the same time, although brain volume is determined at age 12 years,[43] opportunities for education and intellectual development are present throughout a lifetime. Thus, greater intellectual activity and healthy lifestyles may have future implications for prevalence and incidence of dementia.

\section{CONCLUSIONS}

The Playa Study on Dementia and Alzheimer's (EDAP) corroborates that dementia and Alzheimer's disease constitute an important and growing health problem for our country due to the accelerated aging of the Cuban population. It also underlines the 
importance of early diagnosis and proper treatment of hypertension and other vascular risk factors, as well as the need for a national program for the prevention and early diagnosis of dementias and Alzheimer's disease, targeting the elderly and at-risk population in general.

Epidemiological studies using similar designs and diagnostic criteria, carried out in developing countries undergoing demographic transition, will provide highly valuable data for developing more coherent health policies and strategies for patients and their families.

\section{ACKNOWLEDGEMENTS}

This study was carried out as part of the National Program for Attention to Disabled Persons. Our thanks to all the physicians and health professionals, elderly persons and family members who participated. - 1 -

\section{REFERENCES}

1. Ferri CP, Prince M, Brayne C, Brodaty H, Fratiglioni L, Ganguli M, et al. Global prevalence of dementia: a Delphi consensus study. Lancet. 2005;366(9503):2112-7.

2. Mackay J, Mensah G. The Atlas of Heart Disease and Stroke. Geneva: World Health Organization; 2004

3. Wimo A, Winblad B, Jönsson L. An estimate of the total worldwide societal costs of dementia in 2005. Alzheimer's Dement. 2007 Apr;3(2):81-97.

4. The 10/66 Dementia Research Group. Methodological issues in population-based research into dementia in developing countries. A position paper from the 10/66 Dementia Research Group. Internat J Geriatric Psychiatry. 2000;15:21-30.

5. Prince M. Dementia in Developing Countries. Internat Psychogeriatrics. 2001;13(4):389-93.

6. Strong K, Mathers C, Leeder S, Beaglehole R. Preventing chronic diseases: how many lives can we save? Lancet. 2005;366(9496):1578-82.

7. Anuario Estadístico de Salud 2006. Havana: Ministry of Public Health (CU), National Statistics Division; 2007.

8. Folstein MF, Folstein SE, McHugh PR. Minimental state. A practical method for grading the cognitive state of patients for the clinician. J Psychiatr Res. 1975;12:189-98.

9. Hughes CP, Berg L, Danziger WL. A new clinical scale for staging of dementia. Br J Psychiatry. 1982 Jun;140:566-72.

10. Mirra SS, Heyman A, McKeel D, Sumi SM, Cxrain BJ, Brownlee LM, et al. The Consortium to Establish a Registry for Alzheimer's Disease (CERAD) (part II): standardization of the neuropathologic assessment of Alzheimer's disease. Neurology. 1991;41:479-86.

11. Lawton MP, Brody EM. Assessment of older people: self-maintaining and instrumental activities of daily living. Gerontologist.1969;9(3):179-86.

12. American Psychiatric Association. Diagnostic and Statistical Manual of Mental Disorders. 4th ed. Washington DC: AMA; 1994.

13. McKhann G, Drachman D, Folstein M, Katzman $\mathrm{R}$, Price D, Stadlan EM. Clinical diagnosis of Alzheimer's disease: report of the NINCDS-ADRDA Work Group under the auspices of Department of Health and Human Services Task Force on Alzheimer's Disease. Neurology. 1984;34:939-44.

14. Roman GC, Tatemichi TK, Erkinjuntti T, Cummings JL, Masdeu JC, Garcia JH, et al. Vascular dementia: Diagnostic criteria for research studies. Report of the NINDS-AIREN International Workshop. Neurology. 1993;43:250-60.

15. McKeith IG, Perry RH, Fairbairn AF, Jabeen $S$, Perry EK. Operational criteria for senile de- mentia of Lewy body type (SDLT). Psychol Med.1992;22(4):911-22

16. Lobo A, Saz P, Marcos G, Roy JF, Grupo Zarademp. El Estado del Proyecto Eurodem: epidemiología de las demencias en Europa. In: Alzheimer 2003 ¿qué hay de nuevo? 1st ed. Madrid: AULA MÉDICA; 2003. p. 13-9.

17. Llibre Rodríguez J, Valhuerdi A, Sánchez II, Reyna C, Guerra MA, Copeland JRM, et al. The prevalence, correlates and impact of dementia in Cuba. A 10/66 Group population-based survey. Neuroepidemiology. 2008;31:243-51.

18. Llibre Rodríguez JJ, Ferri CP, Acosta D, Guerra M. Prince M. Prevalence of dementia in Latin America, India, and China: a population-based cross-sectional survey. Lancet. 2008 Aug 9;372(9637):464-74. Epub 2008 Jul 25.

19. Pradilla $A G$, Vesga $A B$, Leon-Sarmiento FE. National neuroepidemiological study in Colombia (EPINEURO). Rev Panam Salud Pub. 2003;14:104-11.

20. Herrera E Jr, Caramelli P, Silveira AS, Nitrini R. Epidemiologic survey of dementia in a communitydwelling Brazilian population. Alzheimer Dis Assoc Disord. 2002 Apr-Jun;16(2):103-8.

21. Scazufca M, Menezes PR, Vallada HP, Crepaldi AL, Pastor-Valero M, Coutinho LM, et al. High prevalence of dementia among older adults from poor socioeconomic backgrounds in Sao Paulo, Brazil. Int Psychogeriatr. 2008;20:394-405.

22. Ketzoian C, Rega I, Caseres R, Dieguez E, Coirolo G, Scaramelli A, et al. Estudio de la prevalencia de las principales enfermedades neurológicas en una población del Uruguay. La Prensa Médica Uruguaya. 1997;17:9-26.

23. Llibre JJ, Guerra MA, Pérez-Cruz H. Dementia syndrome and risk factors in adults aged over 60 residing in La Habana. Rev Neurol. 1999;29:908-11.

24. Molero AE, Pino-Ramirez G, Maestre GE: High prevalence of dementia in a Caribbean population. Neuroepidemiology. 2007;29:107-12.

25. Lopes MA, Bottino CM. Prevalence of dementia in several regions of the world: analysis of epidemiologic studies from 1994 to 2000. Arq. Neuropsiquiatr. 2002 Mar;60(1):61-9.

26. McDowell I, Hill G, Lindsay J. Canadian study of health and aging: study methods and prevalence of dementia. Can Med Assoc J. 1994; 150:899-913.

27. Erkinjuntti T, Ostbye T, Steenhuis R, Hachinski $V$. The effect of different diagnostic criteria on the prevalence of dementia. N Engl J Med. 1997:337:1667-74

28. Prince M. Commentary: Two-phase surveys. A death is announced; no flowers please. Int J Epidemiol. 2003;32:1078-80.
29. Tang MX, Cross $P$, Andrews $H$, Jacobs DM, Small $S$, Bell $K$, et al. Incidence of $A D$ in African-Americans, Caribbean Hispanics, and Caucasians in northern Manhattan. Neurology. 2001:56:49-56.

30. Livingston G, Leavey G, Kitchen G, Manela M, Sembhi S, Katona C. Mental health of migrant elders - The Islington study. $\mathrm{Br} \mathrm{J}$ Psychiatry. 2001;179:361-6.

31. Perkins P, Annegers JF, Doody RS, Cooke N, Aday L, Vernon SW. Incidence and prevalence of dementia in a multiethnic cohort of municipal retirees. Neurology. 1997;49:44-50.

32. Maestre GE, Pino-Ramirez G, Molero AE, Silva ER, Zambrano R, Falque L, et al. The Maracaibo Aging Study: population and methodological issues. Neuroepidemiol. 2002;21:194-201.

33. Llibre JJ, Sánchez M. Epidemiología de las demencias y la enfermedad de Alzheimer en la población cubana. Actas del III Forum Internacional de Ciencia e Innovación Tecnológica; 2006 Nov 27-29; Havana, Cuba. Havana: MINSAP;2006.

34. Prince $M$, Llibre JJ, Noriega L, López A Acosta D, Albanese E, et al. The 10/66 Dementia Research Group's fully operationalised DSM-IV dementia computerized diagnostic algorithm, compared with the 10/66 dementia algorithm and a clinician diagnosis: a population validation study. BMC Public Health. 2008;8:219-31.

35. Fratiglioni L, Wang HX. Brain reserve hypothesis in dementia. J Alzheimers Dis. 2007:12:11-22.

36. Manly JJ, Schupf N, Tang MX, Weiss CC, Stern Y. Literacy and cognitive decline among ethnically diverse elders. In: Stern Y, editor. Cognitive reserve: theory and applications. New York: TayIor \& Francis; 2007. p. 219-35.

37. McDowell I. Alzheimer's Disease: Insights From Epidemiology. Aging. 2001;13:143-62.

38. Hofman A, Ott A, Breteler MMB, Bots ML, Slooter AJC, van Harskamp F, et al. Atherosclerosis, apolipoprotein $\mathrm{E}$, and prevalence of dementia and Alzheimer's disease in the Rotterdam Study. Lancet. 1997;349:151-4.

39. Luchsinger JA, Reitz C, Honig LS, Tang MX, Shea S, Mayeux R. Aggregation of vascular risk factors and risk of incident Alzheimer disease. Neurology. 2005;65(4):545-51.

40. Hill G, Connelly J, Hebert R, Lindsay J, Millar W. Neyman's bias re-visited. J Clin Epidemiol. 2003;56(4):293-6

41. Skoog I, Lernfelt B, Landahl S, Palmertz B, Andreasson LA, Nilsson L, et al.15-year longitudinal study of blood pressure and dementia. Lancet. 1996;347(9009):1141-5. 
42. Kivipelto M, Helkala EL, Laakso MP, Hanninen T, Hallikainen M, Alhainen K, et al. Midlife vascular risk factors and Alzheimer's disease in later life: longitudinal, population based study. BMJ. 2001 Jun 16;322(7300):1447-51.

43. Lenroot RK, Giedd JN. Brain development in children and adolescents: insights from anatomical magnetic resonance. Neurosci Biobehav Rev. 2006;30(6):718-29.

\section{THE AUTHORS}

Juan de Jesús Llibre Rodríguez (Corresponding Author: mguerra@infomed.sld.cu), internist. Full professor, Higher Institute of Medical Sciences of Havana, and Chair, Department of Clinical Medicine, Finlay-Albarrán Medical School, Havana, Cuba.
Yuriem Fernández García, psychologist and neurocience specialist, Cuban Neuroscience Center, Havana, Cuba.

Beatriz Marcheco Teruel, clinical geneticist. Assistant professor and director, National Medical Genetics Center, Havana, Cuba.

Nereyda Contreras Hernández, geriatrician and gerontologist, Playa Municipal Health Department, Havana, Cuba.

Ana M. López Medina, geriatrician and gerontologist. Satisfactory aging specialist, Héroes del Corinthia Polyclinic, Plaza Municipality, Havana, Cuba.

Marta Otero Esteve, psychologist, 19 de Abril Polyclinic, Havana, Cuba.
Isis Gil Sánchez, psychiatrist and satisfactory aging specialist. Director, Playa Municipal Mental Health Center, Havana, Cuba.

Milagros Guerra Hernández, psychiatrist and satisfactory aging specialist, 27 de Noviembre Polyclinic, Havana, Cuba.

Milagros García Klibanski, psychiatrist and social psychiatry specialist, 14 de Junio Polyclinic, Havana, Cuba.

Héctor Bayarre Vea, biostatistician. Full professor, National School of Public Health, Havana, Cuba

Submitted: August 13, 2008

Approved for publication: February 27, 2009

\section{Errata}

Page 29, Abstract, Introduction, final sentence should read: "Its population of 11.2 million is aging rapidly: by the year 2020 it is estimated that personas aged $\geq 60$ years will comprise $21.6 \%$ of the population, making Cuban society the "oldest" in Latin America."

Page 29, Introduction, paragraph 4 should read: "Cuba is a developing country with health indicators similar to those of developed countries and a rapidly aging population of 11.2 million. By the year 2020 Cuba will have the oldest population in Latin America, with adults aged $\geq 60$ years accounting for $21.6 \%$ of total population."

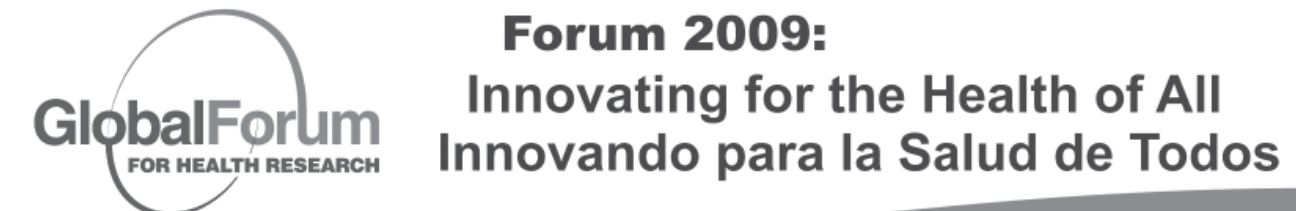

\section{Havana, Cuba 16-20 November 2009}

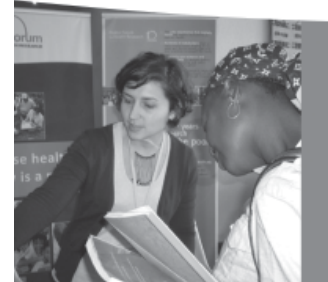

The Global Forum for Health Research is pleased to announce that its 2009 annual Forum will take place in Havana, Cuba from 16-20 November 2009 at the invitation of the Ministry of Public Health. It will focus on incentives and new approaches to strengthen both social and technological innovation for health and health equity.

Who should attend?

Forum 2009 will bring together some 800 decision-makers in funding, research and policy to engage in dialogue, identify lessons learned from experience and identify pathways to solutions. You will have the opportunity to network with participants from health- and science-related ministries, R\&D institutions and academia, development agencies and foundations, nongovernmental organizations, civil society, the private sector and the media from around the world.

\section{What is the theme?}

"Innovation for health" encompasses the entire process from the generation of new ideas; to their transformation into useful services, products, methods, management practices and policies; and their implementation. You will be able to learn about and discuss topics such as building effective national health innovation systems, social entrepreneurship for health, knowledge translation platforms, "innovation indicators" for emerging countries and global innovation policy research networks.

For more information about the Global Forum for Health Research and Forum 2009, and to sign up for the Forum 2009 news list, visit our web site www.globalforumhealth.org.

\section{Registration opens 1 March.}

The Global Forum for Health Research is an independent international organization committed to demonstrating the essential role of research and innovation for health and health equity, benefiting poor and marginalized populations. 